\title{
Trial Research on Influence of Steering Stiffness on Steering Wheel Jitter with Engine Idling
}

\author{
XianYu ${ }^{1 *}$, Huizhen Duan ${ }^{2}$, Xing Li ${ }^{3}$ and Huashan $\operatorname{Lin}^{4}$ \\ ${ }^{1}$ Xiamen University Tan Kah Kee College, China \\ ${ }^{2}$ Zhengzhou University Science and Technology, China \\ ${ }^{3}$ Xiamen Institute of Technology, China \\ ${ }^{4}$ Xiamen King Long United Automotive Industry Co.,Ltd, China
}

Keywords: Jitter with Engine Idling, Automobile NVH, Steering Stiffness

\begin{abstract}
Driving fatigue and even arm numbness can be caused by steering wheel jitters with engine idling. Objective measurement and subjective evaluation are applied of the analysis on the influencing factor of steering wheel jitter in two conditions, engine idling with air conditioning on and off. The prior optimization on steering system stiffness result shows that steering wheel vibration center acceleration is $0.053 \mathrm{~g}$ when the air condition is off, as reduced by $30 \%$, this value reduced to $0.139 \mathrm{~g}$ when the air conditioner is activated, as reduced by $26 \%$. The first order frequency of the steering system is higher than $32 \mathrm{~Hz}$, having avoided the engine idle vibration frequency .The score of subjective evaluation with air conditioning off and on is 6 and 6.5 respectively, as acceptable.
\end{abstract}

\section{Introduction}

Vehicle vibration comfort evaluation is an important part of automobile NVH (Noise, Vibration, Harshness)[1,2]. Driving fatigue and even arm numbness can be caused by steering wheel jitters with engine idling with a vibration frequency of $10-30 \mathrm{~Hz}$.

The main vibration source here is the engine when the automobile is in idling[3,4]. Vibration isolation, vibration waken, and manufacturing of components in order for vibration frequency of the engine to be avoided, are common methods for vibration influence reduction of the engine onto other systems[5,6]. In this paper, an automobile is utilized as a research object, whereas the research method is the combination of objective parameter measurements and subjective evaluations, steering wheel center acceleration and steering system model tests for steering system stiffness (prior and following optimization) is completed, the influencing factor of steering system stiffness on steering wheel jitters is analyzed and the corresponding solution is extracted according to testing data comparisons.

\section{Objective Parameter Measurement and Subjective Evaluation Prior Optimization}

Objective Parameter Measurement Introduction. Objective parameter test mainly refers to a measurement of vibration acceleration of the center of the steering wheel and the mode of the steering system[7].

During the measurement of vibration acceleration of the steering wheel center, three acceleration sensors are mounted on the steering wheel center, the engine is started and the steering wheel center vibration acceleration value in the $\mathrm{X}, \mathrm{Y}, \mathrm{Z}$ directions is collected with engine idling (air conditioning on and off).

Natural frequency of the steering system (Including instrument cross beam assembly, steering column and corresponding bracket) is measured when the engine is off.

Subjective Evaluation Introduction. Subjective evaluation score of the steering wheel vibration 
comfort in the engine idle running state (air conditioning on and off) is mainly submitted by professionals according to subjective feelings and experience[8,9]. Basic subjective evaluation score standard is presented in Table 1.

Table 1. Basic subjective evaluation score standard

\begin{tabular}{|l|l|l|l|}
\hline Score & Description & Score & Description \\
\hline 1 & unbearable & 6 & acceptable \\
\hline 2 & Uncomfortable & 7 & Good \\
\hline 3 & Unacceptable at all & 8 & Very good \\
\hline 4 & unacceptable & 9 & excellent \\
\hline 5 & Needs Improvement & 10 & Very excellent \\
\hline unacceptable & \multicolumn{2}{|l|}{ acceptable } \\
\hline
\end{tabular}

Analysis on Acceleration of the Steering Wheel Center Test Data. According to the aforementioned method, the vibration acceleration value of the steering wheel center is tested when the air condition is turned on and off. The test data are presented in Table 2.

Table 2. Acceleration at steering wheel center (prior optimization)

\begin{tabular}{|l|l|l|l|}
\hline \multicolumn{4}{|l|}{ Acceleration with air conditioning on $/ 10^{-2} \mathrm{~g}$} \\
\hline $\mathrm{X}$ & $\mathrm{Y}$ & $\mathrm{Z}$ & Sum \\
\hline 4.7 & 7.4 & 8.9 & 12.5 \\
\hline Acceleration with air conditioning off $/ 10^{-2} \mathrm{~g}$ \\
\hline $\mathrm{X}$ & $\mathrm{Y}$ & $\mathrm{Z}$ & Sum \\
\hline 12.7 & 21.3 & 9.4 & 26.5 \\
\hline
\end{tabular}

It is concluded that steering wheel vibration center acceleration is $0.125 \mathrm{~g}$ when the air condition is off, being higher than the actual value of $0.05 \mathrm{~g}$; this value reached $0.265 \mathrm{~g}$ when the air condition is activated, being further higher than the actual value of $0.1 \mathrm{~g}$. The test data in both conditions exceeded the actual values, signifying that steering wheel jitters are significantly apparent and affected the driver's comfort during driving.

Analysis on Natural Frequency Test of Steering System. The center of the steering wheel constituted the test point; the engine is not started, whereas the vibration frequency in all three directions of the steering system test data is presented in Table 3.

Table 3. Frequency of steering system (prior optimization)

\begin{tabular}{|l|l|l|}
\hline \multicolumn{3}{|l|}{ Frequency of steering system(first order) $/ \mathrm{Hz}$} \\
\hline $\mathrm{X}$ & $\mathrm{Y}$ & $\mathrm{Z}$ \\
\hline 23.1 & 25.2 & 50.0 \\
\hline
\end{tabular}

According to the reference, the second order modes of the engine with idling is $26 \mathrm{~Hz}$ (air conditioning on) and $28.5 \mathrm{~Hz}$ (air conditioning off)[10,11]. According to the test results, it can be concluded that the first order natural modal frequencies of the steering system in the $\mathrm{X}$ and $\mathrm{Y}$ directions are similar to the second order modes of the engine.

Subjective Evaluation. The following results provided by Professionals according to personal 
feelings on shaky steering wheels are that the score of subjective evaluation with the air conditioning at off is 5, as unacceptable and required improvement, the score of subjective evaluation with the air conditioning at on is 5 , as also unacceptable.

According to the analysis of objective parameter measurement data and the subjective evaluation results, it can be discovered that when the engine is idling, the test data of the steering wheel vibration in two conditions (air conditioning on and off) exceeded the value of experience and the subjective evaluation is not acceptable, therefore steering system stiffness should be optimized.

\section{Design and Test of Optimization Scheme}

Optimization Scheme Design. In order for the modal frequency of the steering system to be improved, mainly aimed at the improvement of steering system stiffness, being the instrument beam, the steering column bracket should be increased and the connection of the two parts should be optimized. Therefore, optimization can be executed out from the following aspects:

(1) instrument beam optimization

As the installation carrier is a part of the steering column, the optimization of the instrument beam constitutes an important factor in the frequency promotion of the entire system[12]. According to mechanical analysis, the triangle support is welded in the middle of the instrument table for an increase in strength, as presented in Fig.1.

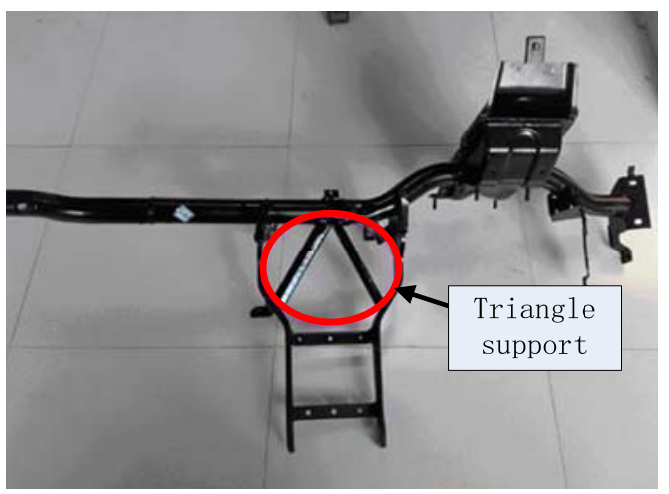

Fig 1. Instrument beam optimization

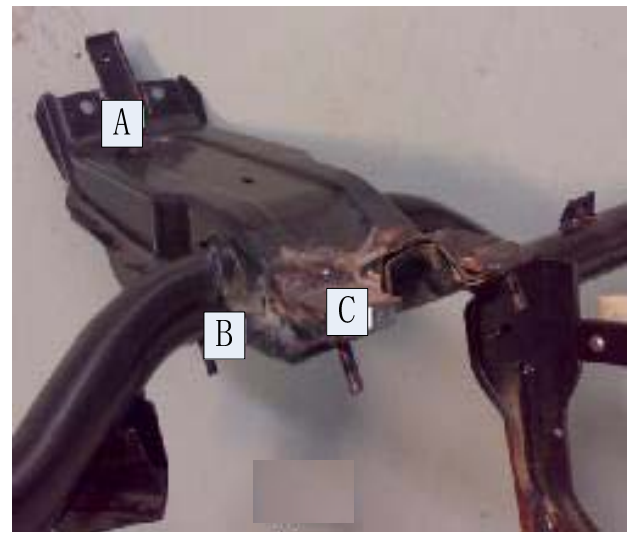

Fig 2. Welding strengthen points

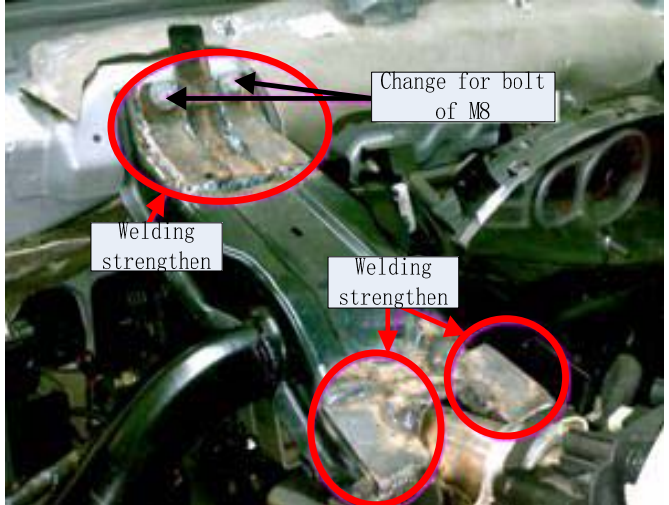

Fig 3. Welding effect chart

(2) column bracket optimization

The strength of the steering column bracket is very important to system stiffness,asit can be 
utilized for steering column support and is fixed on the instrument beam. The three points (A, B, C) in Fig. 2 are strengthened by welding. The welding effect chart is presented in Fig.3

(3) connection optimization

Bolts are utilized for connection of the steering column bracket and the instrument beam, therefore it is required for the locking torque to be improved or an increase in the number of locking bolts. Firstly, the bolt of M6 is replaced by a bolt of M8 at point A(presented in Fig.3) and secondly two bolts are utilized at point $\mathrm{C}$ (presented in Fig.2)

Test of Optimization Scheme. Each optimization scheme is tested, and the test data is presented in Table 4.

Table 4. Improvement of steering system

\begin{tabular}{|c|l|l|l|}
\hline \multirow{2}{*}{ No. } & \multirow{2}{*}{ optimization scheme } & \multicolumn{2}{|c|}{ Test data $/ \mathrm{Hz}$} \\
\cline { 3 - 4 } & & $\mathrm{X}$ & $\mathrm{Y}$ \\
\hline \multirow{2}{*}{ (1) } & triangle support is welded in the middle of the instrument table & 0.4 & $/$ \\
\hline \multirow{2}{*}{ (2) } & Point A welding increase & 0.4 & $/$ \\
\cline { 2 - 4 } & Point B, C welding increase & 0.9 & $/$ \\
\hline \multirow{2}{*}{ (3) } & replace the bolt of M6 into M8 bolt at point in point A & 5.2 & 1.9 \\
\cline { 2 - 4 } & increase two M8 bolts at point C & 1.6 & 3.8 \\
\hline
\end{tabular}

It can be observed from Table4 that the steering system frequencies in $\mathrm{X}, \mathrm{Y}$ directions are improved by $5.2 \mathrm{~Hz}$ and $1.9 \mathrm{~Hz}$ respectively, through a bolt of $\mathrm{M} 6$ replacement by an $\mathrm{M} 8$ bolt at point $\mathrm{A}$ (definition of $\mathrm{A}, \mathrm{B}, \mathrm{C}$ point is presented in Figure 2), and improved by $1.6 \mathrm{~Hz}$ and $3.8 \mathrm{~Hz}$ respectively, by two M8 bolts at point $\mathrm{C}$. It can be concluded that the natural frequency of the steering system is apparently affected by the connection between the steering column bracket and instrument beam optimization.

\section{Objective Parameter Measurement and Subjective Evaluation Following Optimization}

Steering wheel center acceleration test results (following optimization) are presented in Table 5, whereas the steering system modal test is presented in Table 6.

Table 5. Acceleration at steering wheel center (following optimization)

\begin{tabular}{|c|c|c|c|}
\hline \multicolumn{4}{|c|}{ Acceleration with air conditioning on $/ 10^{-2} \mathrm{~g}$} \\
\hline $\mathrm{X}$ & $\mathrm{Y}$ & $\mathrm{Z}$ & Sum \\
\hline 2.1 & 1.9 & 4.5 & 5.3 \\
\hline \multicolumn{4}{|c|}{ Acceleration with air conditioning off $/ 10^{-2} \mathrm{~g}$} \\
\hline $\mathrm{X}$ & $\mathrm{Y}$ & $\mathrm{Z}$ & Sum \\
\hline 7.7 & 3.1 & 11.2 & 13.9 \\
\hline
\end{tabular}

Table 6. Steering system frequency (following optimization)

\begin{tabular}{|c|c|c|}
\hline \multicolumn{3}{|c|}{ Frequency of steering system(first order) $/ \mathrm{Hz}$} \\
\hline $\mathrm{X}$ & $\mathrm{Y}$ & $\mathrm{Z}$ \\
\hline 32.1 & 32.5 & 52.6 \\
\hline
\end{tabular}

It can be concluded that steering wheel vibration center acceleration is $0.053 \mathrm{~g}$ when the air 
condition is off, as reduced by $30 \%$, this value reduced to $0.139 \mathrm{~g}$ when the air conditioner is activated, as reduced by $26 \%$. The data in both conditions is very similar to the experience values of $0.05 \mathrm{~g}$ and $0.1 \mathrm{~g}$. The score of subjective evaluation with air conditioning off and on is 6 and 6.5 respectively, as acceptable.

According to the test data in Table6, the first order frequency of the steering system is higher than $32 \mathrm{~Hz}$, having avoided the engine idle vibration frequency and the optimization effect is good.

\section{Conclusions}

The vibrating steering wheel with the engine idling is mainly caused by lower differences between the steering system and the vibration frequencies of the engine. In order for resonance frequency to be avoided is the solved by steering system stiffness improvement. According to the analysis, the following methods of vibration problems solution are summarized:

(1)optimization of connection

The natural frequency of the steering system is apparently affected by the connection optimization between the steering column bracket and instrument beam.

(2)Comprehensive application of objective measurement and subjective evaluation

According to comfort evaluations of vibration, it is crucial that the combination of objective parameter measurements and subjective evaluation are selected as a research method. The feelings of a driver can be observed by subjective evaluation, and verified by objective measurement, along with the direction of improvement. Therefore the practical problems can be solved by comprehensive application of the aforementioned methods.

\section{Acknowledgements}

This work is financially supported by Fujian Natural Science Foundation (2015J01223), Xiamen University Tan Kah Kee College Incubation project(2015L07) and Zhengzhou University Science and Technology teaching reform project(2016JGYB04).

\section{References}

[1] Wanjun Tan, Liang Yang: submitted toJournal of Vibration Engineering (2011). (In Chinese)

[2] Peters B, Ventura CE: submitted to journal of Mechanical Systems and Signal Processing (2003).

[3] Shuming Chen, Dengfeng Wang, Lili Su: submitted to journal of Chinese Journal of Automotive Engineering (2011). (In Chinese)

[4] Xu Chen, Guorui Li, etc: submitted to journal of Noise and vibration control (2016).(In Chinese)

[5] Lihua Lu, Feng Dan, etc: submitted to journal of Noise and vibration control (2016).(In Chinese)

[6]Gen Wang, Fanping Lin, etc: submitted to journal of He Fei University of Technology ( 2012).(In Chinese)

[7] D.J.EWINS: Modal experiment theory and practice, translated by Chunsheng Zhao, Chuanrong Zhou, Dong Nan university publishing, (1991).

[8] Debao Li, Qiuhai Lu: Analysis on experimental modal and its application, Science Press publishing, (2001). 
[9] Zhendong Zhao: submitted to Journal of Machine Design (2015). (In Chinese)

[10] Huaji Wang, Changfu Zong, etc: submitted to Journal of Mechanical Engineering, (2011).(In Chinese)

[11] Baoguo Ning, Lijun Zhang: submitted to Chinese Journal of Construction Machinery (2004). (In Chinese)

[12] Wenku Shi, Guangming Wu, etc: submitted to Vibration Engineering (2013).(In Chinese) 